\title{
Natural Light in Civic Spaces: A study of the Law Court of Antwerp, Belgium
}

\author{
Zohreh Soleimani $^{1}$ \\ ${ }^{1}$ University of Bath, Department of Architecture and Civil Engineering, Bath, UK \\ Correspondence: Zohreh Soleimani, University of Bath, Department of Architecture and Civil Engineering, Bath \\ BA2 7AY, UK. E-mail: zohreh_soleimani@yahoo.com
}

Received: December 10, 2014 Accepted: December 19, 2014 Online Published: January 29, 2015

doi:10.5539/jsd.v8n1p242

URL: http://dx.doi.org/10.5539/jsd.v8n1p242

\begin{abstract}
Energy-conscious design as a concept can become devalued if natural lighting is not convincing. In fact, day lighting can address both quantitative (provision of task luminance, savings in artificial lighting, passive heat gain) and qualitative (indication of spaces' mood, time/duration of exposure, metabolic rhythms) factors of a sustainable design. This paper evaluates the performance characteristics of applied strategies to meet the quantitative responsibilities of natural lighting in the Law court of Antwerp, constructed with environmentally friendly approach. On the basis of observations and archival documents, the results show that the applied strategies e.g. window, atrium and roof light for enhancement of day light penetration and distribution, besides usage of shading devices e.g. brise soleil and overhangs for protecting the spaces from intense sunlight have both advantages and disadvantages. Further, the potentials to relieve the deficiencies are discussed.
\end{abstract}

Keywords: energy efficiency, green buildings, natural lighting, atrium, roof light

\section{Introduction}

Most people nowadays spend $80-90 \%$ of their time in confined spaces (WHO, 1997), which could cause enhancement in probability of the artificial lighting utilization in order to address the proper illuminance condition. However, it is believed that working long hours exposed to artificial lighting can be injurious to health (SCENIHR, 2012). Further, such proceeding would fully opposite of the bioclimatic architecture goals. In contrast, working in day light is believed to result in less stress and inconvenience, besides provides superb color distinction and color rendering rather than artificial lighting with the same illuminance condition (Edwards \& Torcellini, 2002). Moreover, natural lighting presents a potentially lower energy choice and life-cycle cost as it attempts to apply day light for as long as proper environmental conditions in terms of climate, geographic location, building type and client preferences permit. Consequently, day lighting minimizes energy consumption and $\mathrm{CO} 2$ emissions, relative to artificial lighting, while maintaining visual comfort of occupants.

However, the success of day light strategies mainly appertains to some factors such as the availability of natural light (based on latitude and surrounding conditions of the building, climate and building orientation). Consequently, with regard to a proper environmental condition, advanced day lighting strategies and systems can significantly improve the quality of light in an indoor environment, whereas ignoring them would result in uncomfortable glare, overheating and unwanted artificial lighting. The scope of this work focus on analysis of day lighting strategies and systems applied in the law court of Antwerp constructed with energy conscious approach. The evaluated strategies are the building's orientation and form, windows, shadings, atrium and roof lights.

\section{Method}

This research has an analytical review approach. Its goal is studying and perceiving the past documents and organizing them with an analytical mind. Accordingly, site observation and archival evidences about the Law Court of Antwerp related to the applied strategies for enhancing the natural lighting in the building provide the primary data for the study. Then the collected data are analyzed based on the approved criteria, standards and guidelines relevant to natural lighting. Further, probable solutions for promoting each of the applied strategies are discussed. 


\section{Case Study}

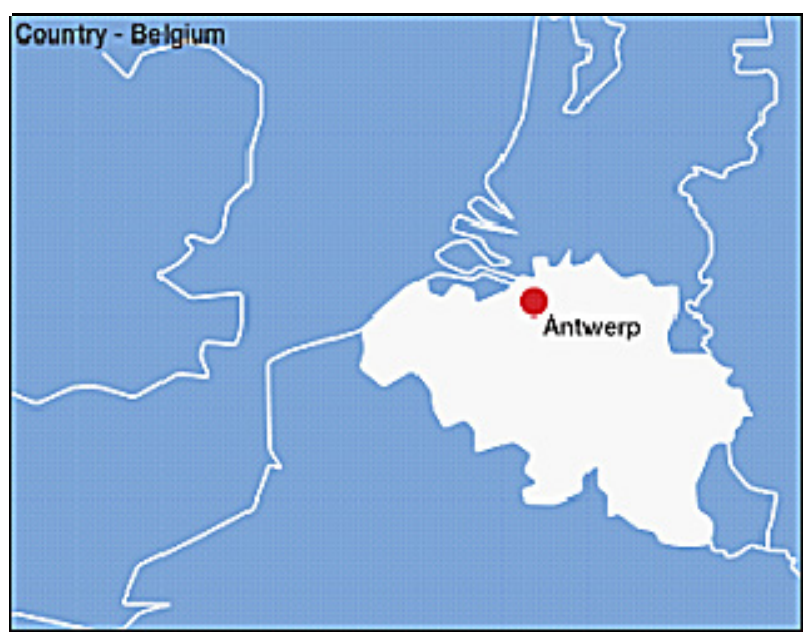

Figure1. Location of Antwerp in Belgium (RSH-P, 2014)

The law court of Antwerp, a part of environmental friendly heating, cooling and ventilation strategies was chosen as the case study for implementation of day lighting. As Figure 1 shows, Antwerp is located in northern of Belgium at an altitude of 14 meters above sea level, within latitude and longitude of 51 degrees $20^{\prime} \mathrm{N}$ and 04 degrees 46' E (Climate-zone, 2004). Since in Antwerp, the shortest day of the year is in October with 8:57 hours of day light; the longest day is in June with 16:34 hours of day light (Climatevo, 2014), the building is receiving adequate amounts of day lighting from the sun, which can be captured for lighting purpose during daytime.

\subsection{Site Map of Location}

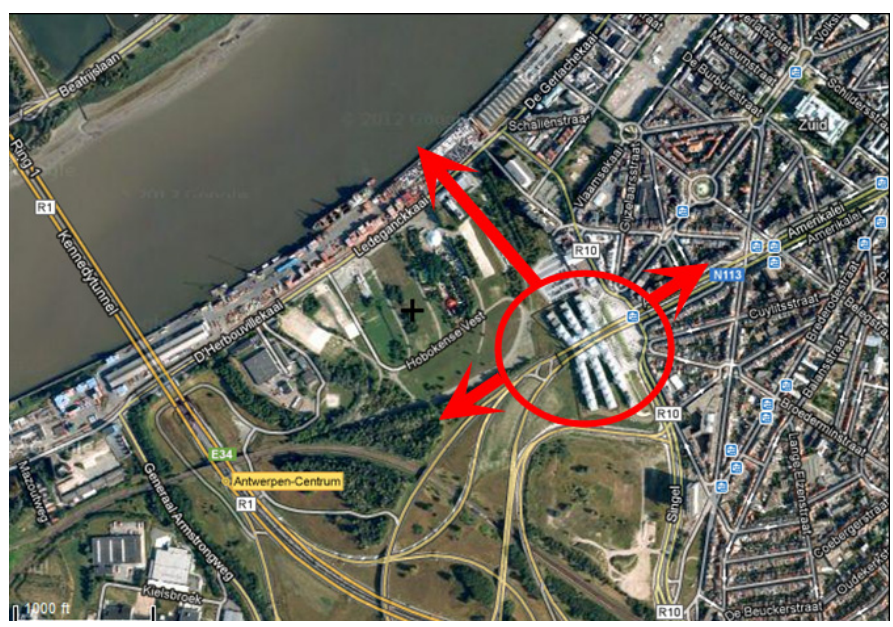

Figure2. Site map of Antwerp Law court and the position of the three surrounding texture

(Googlemap, 2014)

As Figure 2 presents, the new law court of Antwerp is roughly located in the Northwest-Southeast orientation and surrounded by three different types of peripheral textures. In the Northern facades (from Northwest to Northeast), it borders urban fabrics and Amerikala Boulevard, while in the Northwest it faces Schelde river and in the Southern side (from Southeast to Southwest), an open green space is placed in front of that. These external obstructions will influence on sunlight intensity with regard to daytime and season, reflectance value, density, distance, angle and area of the external textures. Table 1 shows the corresponding reflectance value of the peripheral texture that the building is surrounded by. According to the textures distance to the complex and their reflectance value, the highest and the lowest reflectance value vary among the textures with regards to the hot and cold seasons. 
Table1. Environmental texture and the corresponding reflectance value

Environmental Texture and The Corresponding Reflectance Value

Forest(Delicious)

$0.15-0.20$

Asphalt

Grass

$0.16-0.26$

\begin{tabular}{|c|c|c|c|c|}
\hline \multicolumn{5}{|c|}{ Urban Fabric } \\
\hline \multirow[t]{2}{*}{ Concrete } & \multicolumn{3}{|c|}{ Brick } & \\
\hline & \multicolumn{2}{|c|}{0.23} & & 0.3 \\
\hline \multicolumn{5}{|c|}{ Soil } \\
\hline \multirow[t]{2}{*}{ Dark\& Wet Soil } & \multicolumn{2}{|c|}{ Light\& Dry Soil } & Snow covered & \\
\hline & $0.05-0.4$ & $0.15-0.45$ & & 0.4 (old) -0.95 (fresh) \\
\hline
\end{tabular}

Water

Depends on incidence degree: The closer the angle is from 90 to 0 , the reflection is reduced from $100 \%$ to $0 \%$.

(Bembook, 2012), (Scubageek, 2005).

\section{Applied Day Lighting Strategies}

An applicable day lighting strategy should be formulated of simple solutions such as louvers, light-shelves, fixed overhangs and then adaptable dynamic elements such as blinds, movable lamellae, holographic optical elements if adjusting natural light's quantities, distribution and penetration is required. In case of, the law court of Antwerp, only simple elements like siting, form, window, atrium and roof light are implemented.

\subsection{Building Orientation and Form}

Figure 4 shows the sun path diagram for $51^{\circ} \mathrm{N}$ (Antwerp) latitude and the outlined building in the overall orientation of Northwest to the Southeast. With regard to this diagram, except the narrower sides (Northwest and Southeast), the other sides deliver more or less sun rays all over the year,which shows such an orientation is efficient for this latitude.

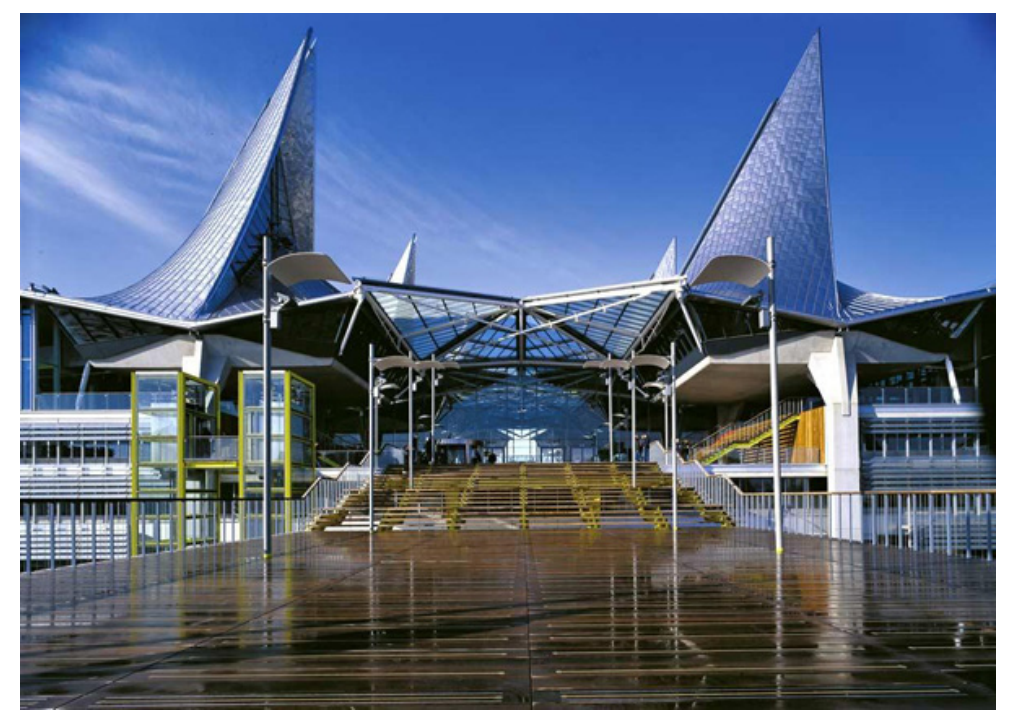

Figure3. Designed atrium and roof lights in Antwerp law court (loc.alize.us, 2006)

Allowing a maximum day light penetration, the volume has been designed in 6 wings layout. In this manner, instead of a wide corridor, there are 6 narrower corridors (14 meter), which let higher penetration of sun rays into 
the depth. The complex is designed in 5 floors that according to services, each floor has a special plan. As an office space, $2^{\text {nd }}, 3^{\text {rd }}$, and $4^{\text {th }}$ floors have the same plan. At these floors, rooms are designed on the outside edge of each wing with $6.25 \mathrm{~m}$ depth, while a corridor (roughly $1.5 \mathrm{~m}$ width) joins them in the middle. As the result, the office rooms are designed passive, while the corridor as a connecting space is a non-passive zone. So the natural light penetrates the office spaces through the facade windows in both sides.

Since eternal obstructions will reduce sunlight and skylight availability, when a window is used as the main light source, external obstructions (oppose facade) should not be higher than $25^{\circ}$ above the horizon. In this case, the Law court, the height of the first floor is 4.6 and the second, third and the fourth ones (office spaces) are each 3 $\mathrm{m}$ height, which is $16.6 \mathrm{~m}$ in total. So the required space between the wings to avoid any obstruction by the $41 \mathrm{~m}$ oppose wing is $83 \mathrm{~m}$. However, the only $37 \mathrm{~m}$ gap is considered in the narrowspace between the wings, showed in the red line in figure4, which precludes day light admittance into the depth of the lower floors and probably it can raise problems of glare and artificial lighting.

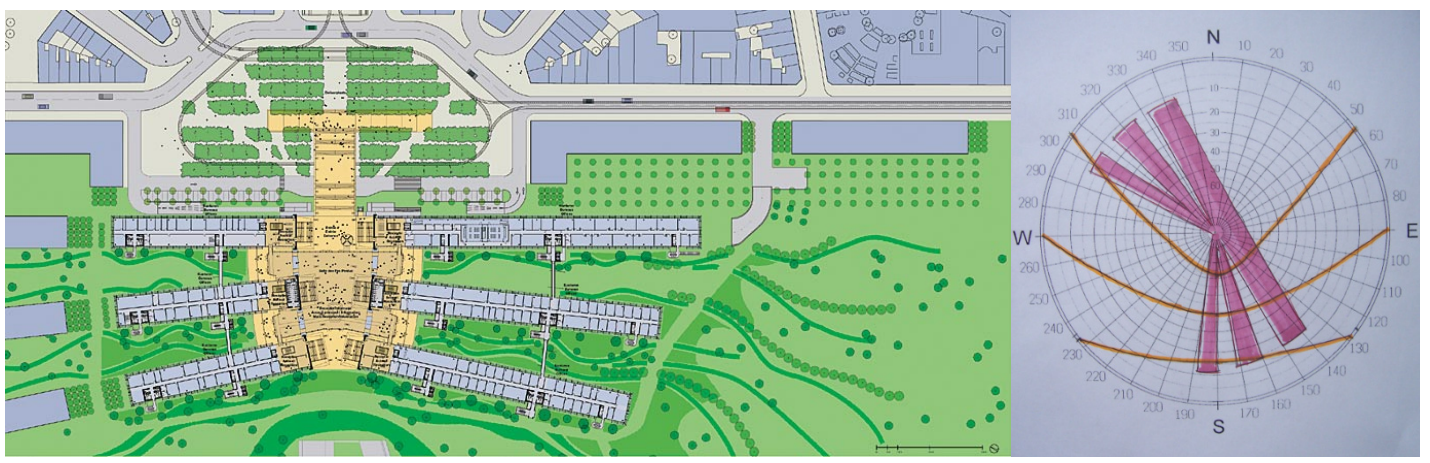

Figure4. Office plan and sun path diagram of the law court of Antwerp (RSH-P, 2014)

\subsection{Windows and Solar Shading Design}

Typical vertical windows with $1.64 \mathrm{~m}$ height are used for providing view and day lighting. The window head height is $2.64 \mathrm{~m}$ with only $30 \mathrm{~cm}$ distance from the ceilings. As the result, great vertical sky components enter the rooms for the great visible sky angle, which can result in glare. Avoiding the glare issue, as figure 5 shows horizontal brise soleil is applied as a shading device. However, sufficient day light can penetrate into space up to twice the window's height. So in this case without the brise soleil half of the rooms is lit naturally while half of the other is within the non sky line(1.64windows height*2>6.25 rooms depth/2). But as soon as the horizontal brise soleil is installed, the entrance of natural light is hindered significantly. Therefore, distribution of day light decreases seriously throughout the rooms, which might evoke artificial lighting demand. Avoiding this problem the applied brise soleil could be replaced with light shelves, which allows day light penetration into the space's depth.

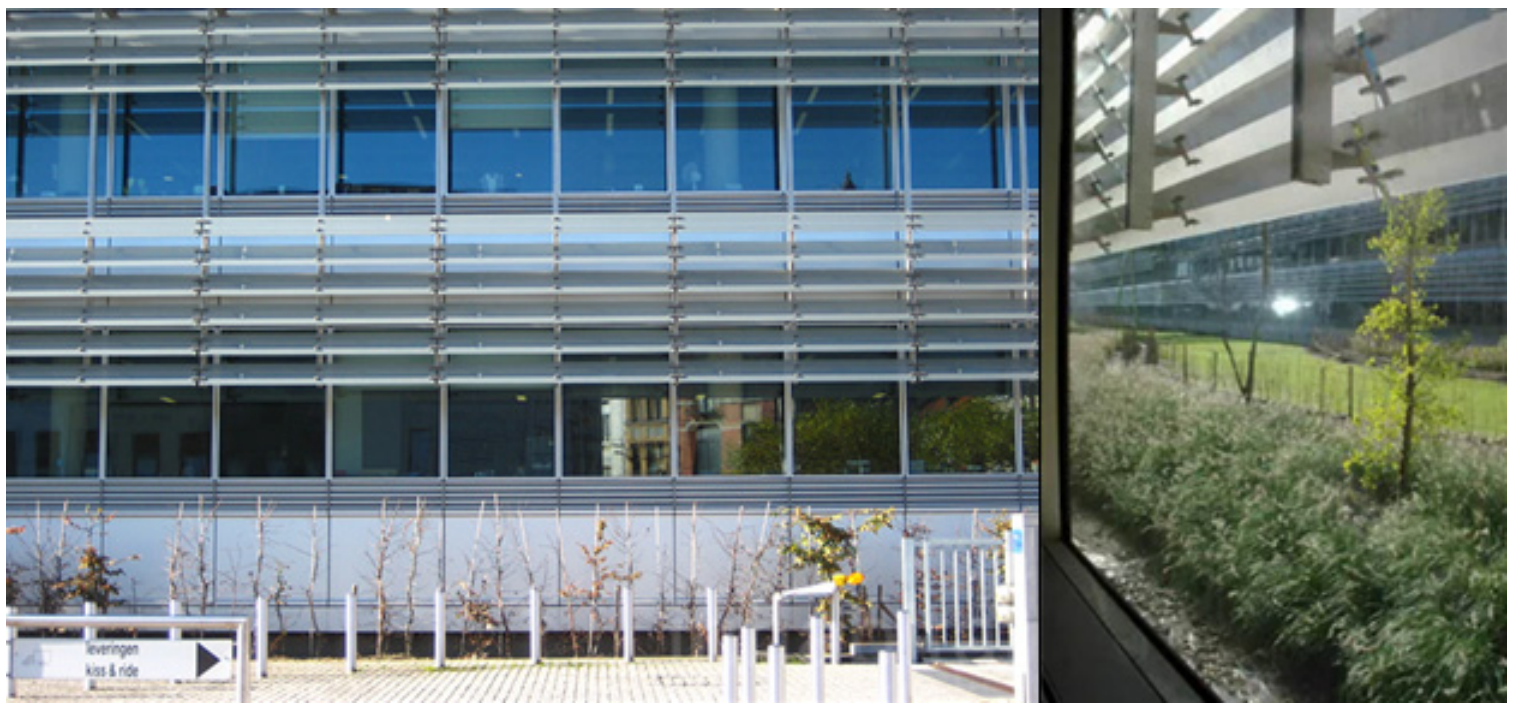

Figure5. Applied brise soleil as shading device (Lisa, 2013) 


\subsection{Atria}

One of the remarkable features of this building is the main atrium located at the center of the complex as a public gathering hall and transparent connection between city center and suburb. This hall is the connecting point of the 6 wings, which makes access to all parts of the Law court as well. The crystalline roof is consisting of high performance glaze and 16 triangular stainless-steel, which add up the glazes together. As a North latitude $\left(51^{\circ}\right)$, the atrium should be designed quite wide to provide a greater sky angle for capturing higher sky components, which is considered appropriately in this complex. Table 2 shows the room index of the atrium and its relative sky components at the center of its floor, which are 0.8 and $47 \%$ respectively.

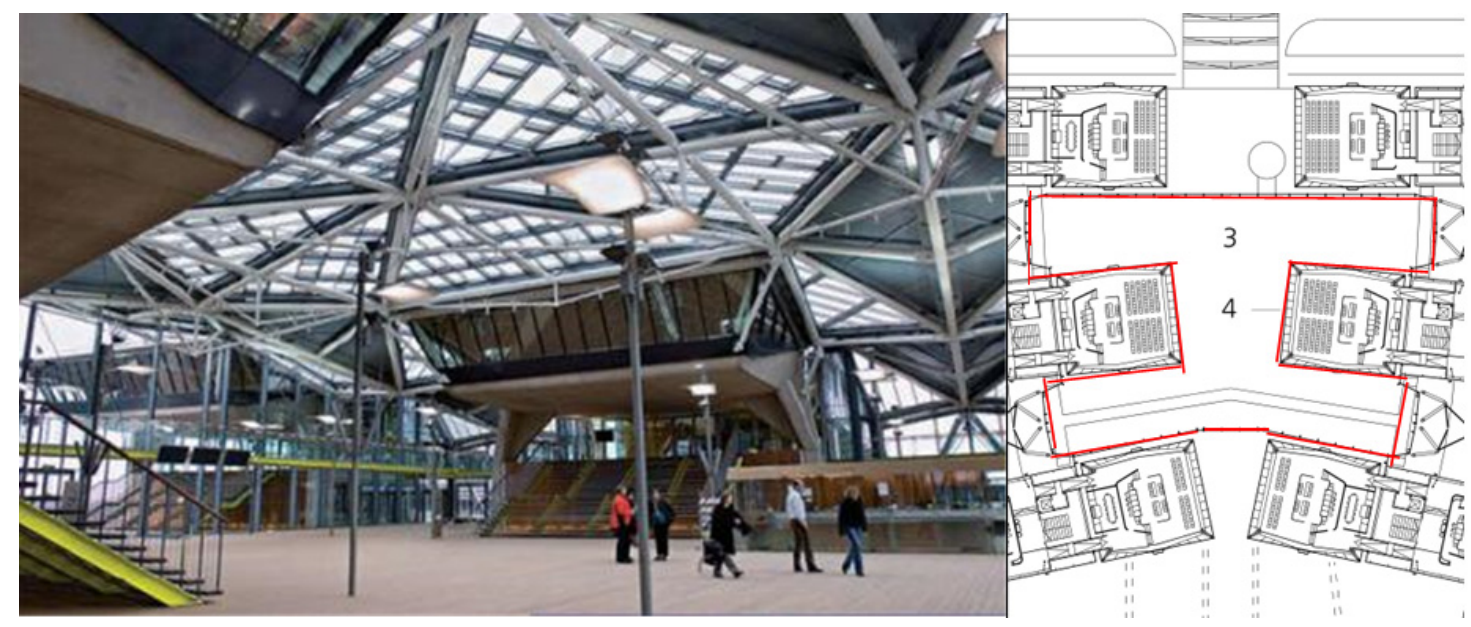

Figure 6. Lay out of the atrium (CivilEng, 2014)

However in practice judging the atrium's day light efficiency is impossible without considering colors and reflectance values of the internal components. As figure6 shows, after passing the atrium crystalline roof, part of the sun's rays hit the glaze of the hearing rooms on the $5^{\text {th }}$ floor and passes through, which reduces the amount of sun's rays reaching the lower levels. The other parts reflected down by concrete frames of hearing rooms, which has bright color. Moreover, metal objects like, structural steels of the roof and stairs, stair railings intensify this reflectance. It should be added that the timbers applied in stairs, connective bridges, and atrium floor takes part in this reflectance either.

Further, this hyperbolic glazing roof provides potential for glare on certain times of the years as figure7 shows. This issue can be resolved via applying dynamic louvers for the atrium to make shade during days whenever and wherever it is required. Moreover, for heat loss potentials of glaze surfaces, the proposed dynamic louvers would also reduce the heat loss as well. 


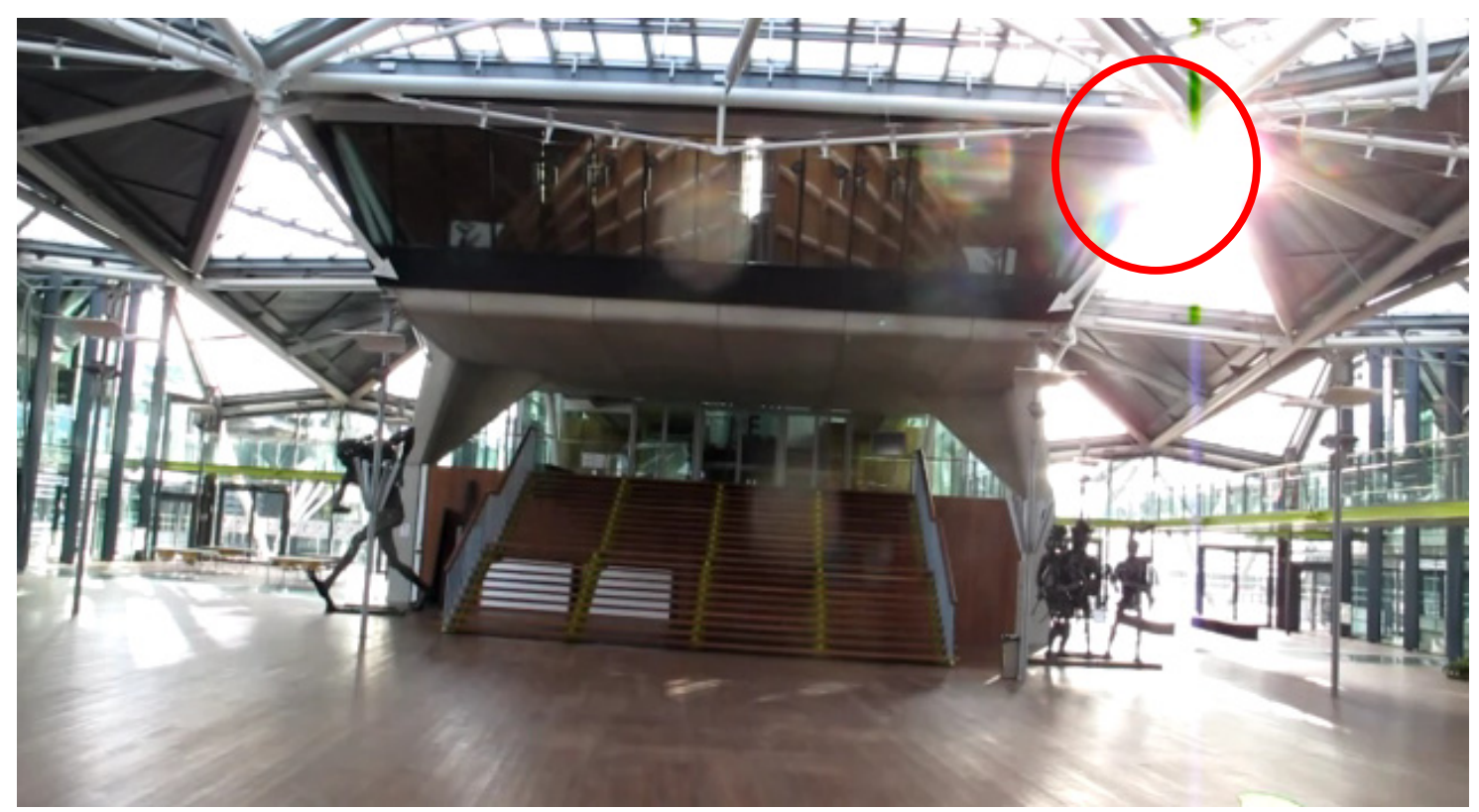

Figure7. Glare issue in the atrium (Maetens, 2012)

Table2. Room Index Ratio of atrium well (Ashley, 2001)

\begin{tabular}{ccccc}
\hline \multicolumn{5}{c}{ Room index of atrium } \\
\hline $\mathrm{L}$ & $\mathrm{W}$ & $\mathrm{L}_{1}$ & $\mathrm{~W}_{1}$ & $\mathrm{H}$ \\
$70 \mathrm{~m}$ & $38.5 \mathrm{~m}$ & $21 \mathrm{~m}$ & $14 \mathrm{~m}$ & $23 \mathrm{~m}$ \\
\hline
\end{tabular}

$\mathrm{Kr}($ Room Index of Atrium $)=(\mathrm{L} \times \mathrm{W}) /\{(\mathrm{L}+\mathrm{W}) \times \mathrm{H}\}$

$\{(70 \times 38.5)-(2 \times 21 \times 14)\} /\{(70+38.5) \times 23\}=\mathbf{0 . 8}$

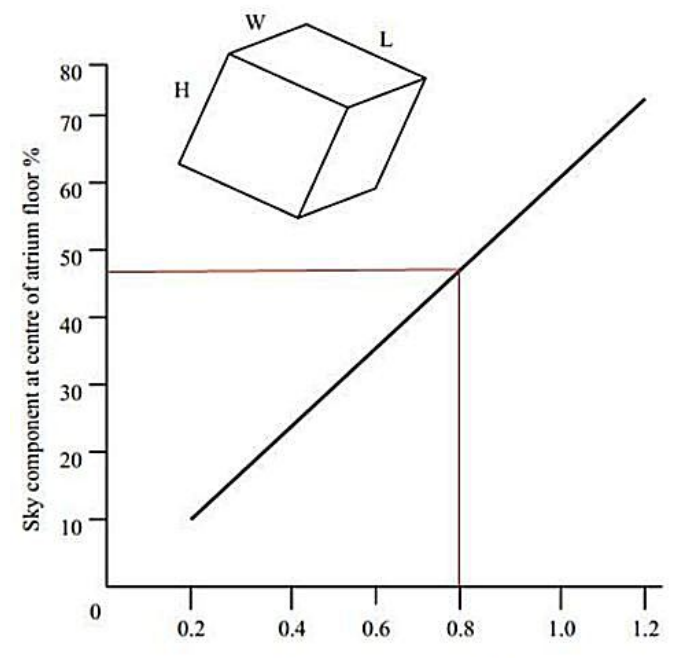

$\mathrm{Kr}$ (Room Index of Atrium) $\mathrm{L} \times \mathrm{W} /(\mathrm{L} \times \mathrm{W}) \times \mathrm{H}$

\subsection{Diffusing Roof Lights}

The Antwerp lawcourt is primarily famous for its complex roof, which is the main landmark of the city. The roof is the symbol of ships' sails, which are crossing the river in present and pass. Precisely, the amazing part of this roof is 32 paraboloid (2 dimensional curved surface) roof lights, which cover the hearing rooms (RSH-P, 2014). In height, the 6 roof lights over the large hearing rooms have $41 \mathrm{~m}$ height from the ground, while the other 26 over the smaller hearing rooms have $26.24 \mathrm{~m}$ height. As seen in figure 8 , all of the roof lights can be divided into 
4 main elements that peaks of the two higher rise up above the smaller ones and providing sufficient space for skylight entrance (RSH-P, 2014).

As seen in table3, the transparent part of all roof lights faces Northwest that based on the related sun path diagram, it is not the prevailing sun path in this latitude. As the result, a majority of the entered lighted into the hearing rooms are the reflected ones from the external finish, which is a $0.5 \mathrm{~mm}$ stainless-steel sheet with continuously welded standing steams (RSH-P, 2014). The entered diffuse light, passes through the internal finish which is a laminated timber on three layers of crosswise planking with a paraboloid geometry and bumps and dents. For this reason, both the incidence and the reflected degrees vary at each part of the internal finish. In fact, for such a unique reflectance value of each part, it acts as a diffuser that distributes moderate light in the hearing rooms as figure 8 shows. It should be added that all roof lights are equipped with louvers or overhangs, which avoid any disturbance caused by direct sun radiation in summer, when the sun is in higher altitude.
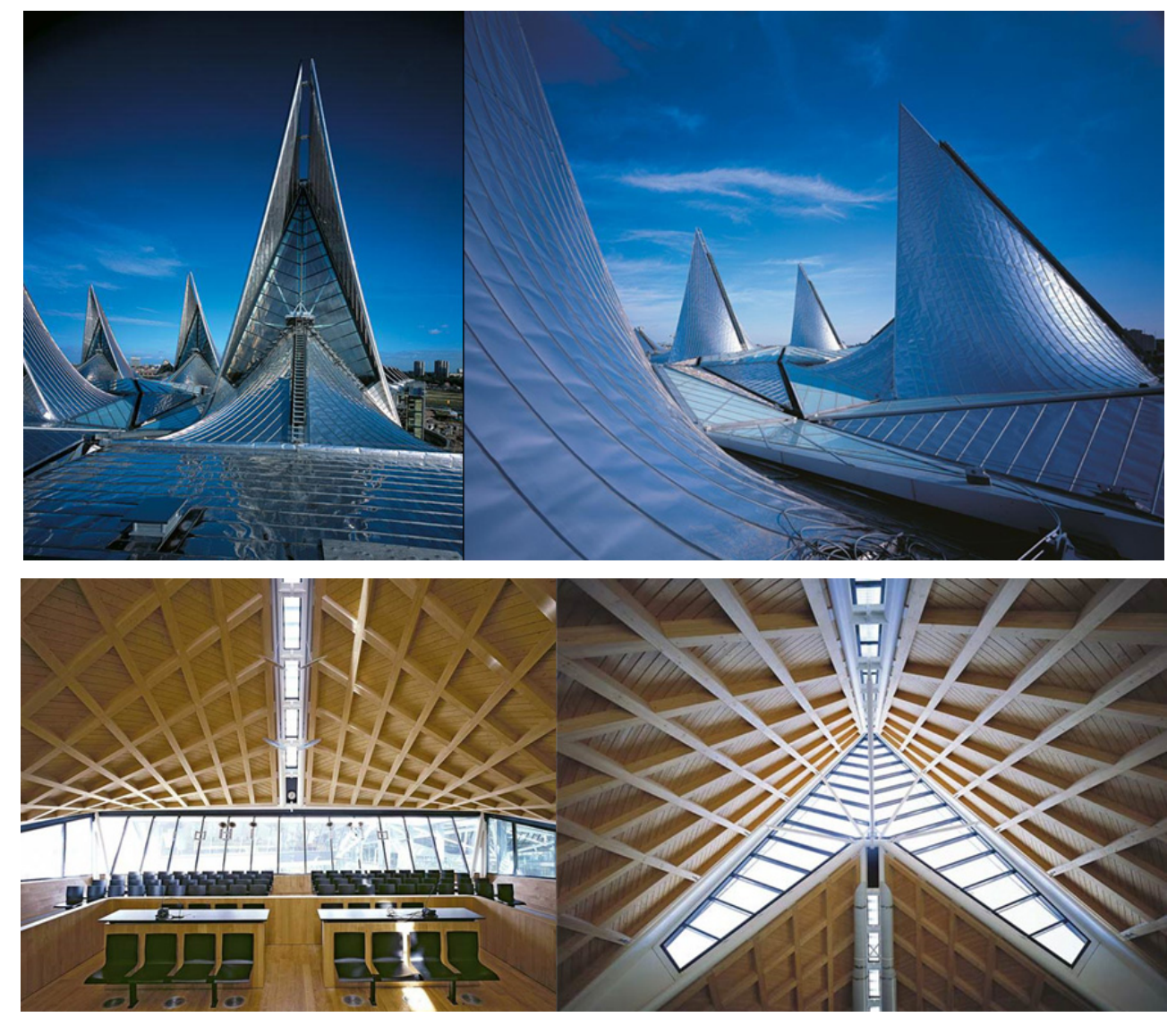

Figure 8. Outside and inside finish of the roof lights

(Evolo, 2012), (Novosibdom, 2014)

For the paraboloid geometry of the designed roof lights over the 32 hearing rooms, they act like lightwells. Therefore, their day light performance are largely depends on both their geometrical aspects and their inner surface reflectance. In terms of geometrical aspects, the proportion of height, length and width of the roof lights play a vital role in the amount and quantity of day light in the hearing rooms. This proportion called well index is the most appropriate index for determining the effect of geometry on day light illumination distribution. According to table 3 the measured well index for the high and low roof lights are 0.83 and 0.4 respectively, whereas a lightwell with proportions of a cube always has a well index of 1.0. 
Table 3. Well index of the roof lights

\begin{tabular}{ccccc}
\hline & Height (roof lights well) & Length & Width & WI \\
\hline High roof lights & 13.12 & 18 & 14 & 0.83 \\
Low roof lights & 6 & 15.5 & 14 & 0.4 \\
\hline
\end{tabular}

$\mathrm{WI}=\{\mathrm{H} \times(\mathrm{W}+\mathrm{L})\} / 2 \times(\mathrm{W} \times \mathrm{L})$

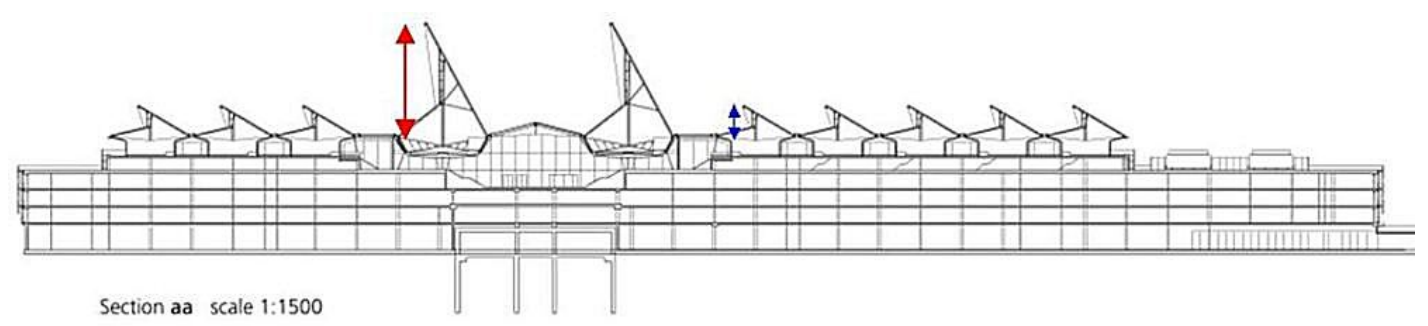

Section of the Antwerp law court (RSH-P, 2014)

In the case of the reflectance value of the inner timber surface, because various types of timbers cover the reflectance between 33\%-67\% (Timbakote, 2014) and the exact type of the applied timber in this complex is not mentioned, $40 \%$ and $60 \%$ are considered as the default reflectance values for the timber. Based on figure 10 , the lightwells efficiency of the lower roof lights with $60 \%$ to $70 \%$ is more than the higher ones with $40 \%$ to $50 \%$. Obviously, the 6 narrower and taller roof lights over the large hearing rooms are less efficient than the wider and shorter ones over the 26 ones. In spite of this deficiency, the glazed body of the large hearing rooms lets the atrium's light to enter the large hearing rooms as figure 9 shows. Therefore, it can be concluded that deliberately lower efficient roof light are designed for large hearing rooms to avoid massive day lighting.

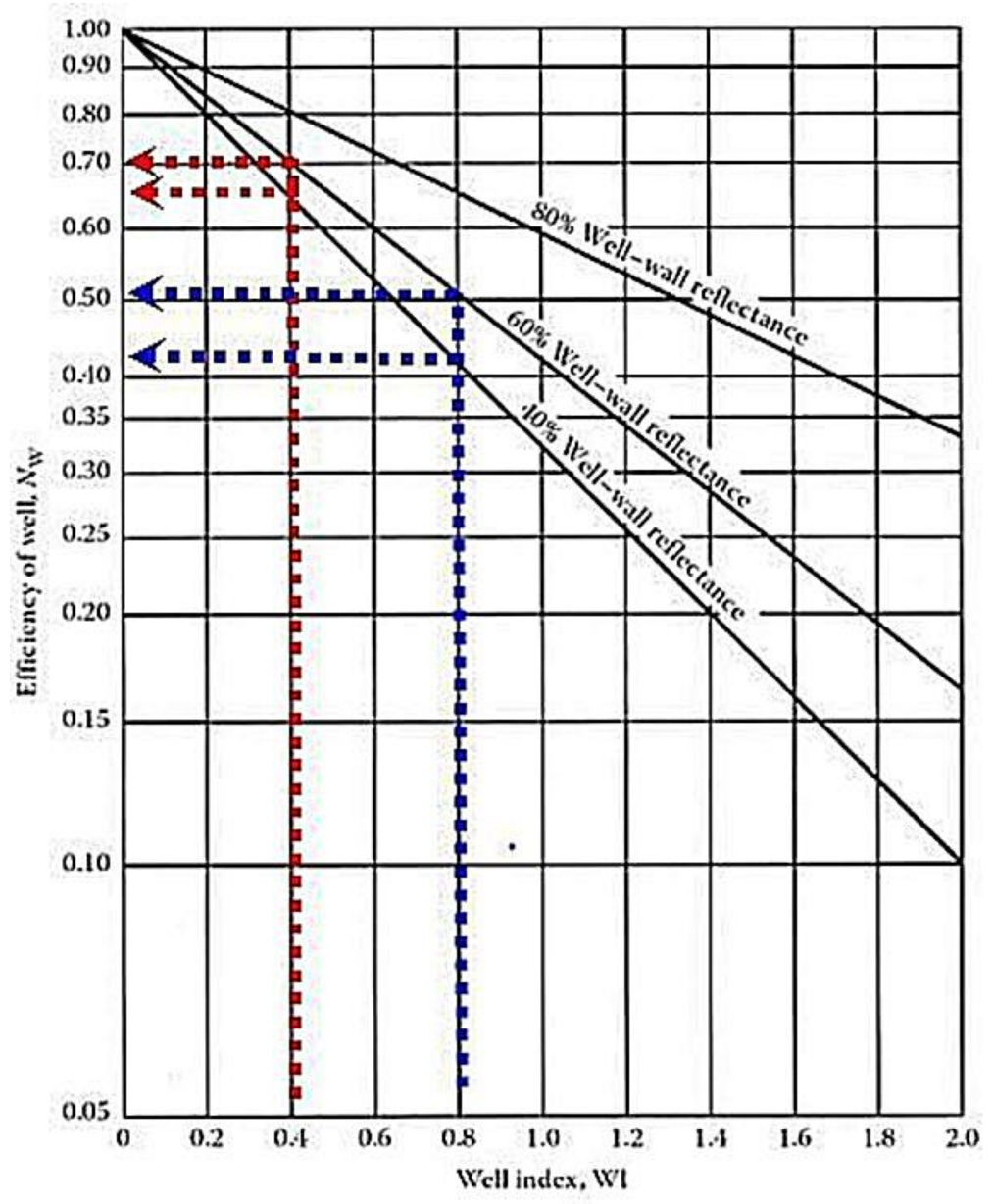

Figure 9. Lightwell efficiency diagram of the law court (Kreith et al., 2010) 


\section{Conclusion}

In this case, scattering of plant into 6 blocks with narrow width instead of one with deeper width, besides orientating from Northwest to Southeast provide proper day light penetration into the building spaces. To decrease the risk of glare and overheating, steel brise-soleil supporting windows that run the full length of the building alongside the windows, which filter any probable glare and increase visual comfort for the users. However, the presence of these brise-soleil decreases the penetration of the light into the spaces, which could be replaced with light shelves to both blocks high-angle sun penetration during summer, while also reflecting incoming radiation deeper into the space.

In addition, an extensive use of glass in the shape of the atrium and roof lights for being the beneficial of skylight admittance and making visual contact with outside could also enhance thermal losses to the outside and increasing heating loads in wintertime. Further lack of proper shadings of the atria can lead to tangible glare, which could be resolved by equipping the atria with dynamic louvers to avoid glare and decreasing the thermal losses.

As a conclusion, in the case of law court of Antwerp, day lighting has shaped the spatial features and design of the building from its early stages of conception and development, specifying the qualitative specifications of internal spaces and conclusively contributing to a building which is less damaging for the environment, cost efficient in the long term, and finally motivating and sensational for its occupants.

\section{References}

Ana Lisa. (2013). Richard Rogers' New Antwerp Law Courts Feature Unique Rainwater-Recycling Rooftops Read more: Richard Rogers' New Antwerp Law Courts Feature Unique Rainwater-Recycling Rooftops | Inhabitat - Sustaina. Retrieved from http://inhabitat.com/richard-rogers-designed-new-law-courts-in-antwerp-recycles-rainwater-from-a-uniquepointed-rooftop

BEMBook. (2012). Ground Reflectance. $\quad$ Retrieved from http://www.bembook.ibpsa.us/index.php?title=Ground_Reflectance

CivilEng. (2014). CivilEng. Retrieved January $17, \quad 2013$, from http://www.civileng.co.il/\%D7\%90\%D7\%93\%D7\%A8\%D7\%99\%D7\%9B\%D7\%9C\%D7\%95\%D7\%AA-a ntwerp-law-courts

Climatevo. (2014). Weather in Antwerp 2014. Retrieved December 5, 2014, from http://climatevo.com/2014,antwerp, be

$\begin{array}{llll}\text { Climate-zone. } & \text { (2004). } & \text { ANTWERP. } & \text { Retrieved }\end{array}$ http://www.climate-zone.com/climate/belgium/celsius/antwerp.htm

Edwards, L., \& Torcellini, P. (2002). Daylighting in the office. In: - A literature review of the effects of natural light on building occupants. colorado: National renewable energy laboratory. 9.

Evolo. (2012). New Antwerp Law Court / Stirk Harbour + Partners. Retrieved from http://www.evolo.us/architecture/new-antwerp-law-court-stirk-harbour-partners

Google maps. (Downloaded 2014). Antwerp, Belgium. Retrieved from http://maps.google.co.uk/maps?hl=en\&tab=wl

J.Ashley. (2001). Modification of Atrium Design to Improve Thermal and Daylighting Performance. Queensland University of Technology.

Kreith, F., Krumdieck, S., \& Kreider, J. F. (2010). Principles of Sustainable Energy. U.S: CRC press. 702.

loc.alize.us. (2006). Antwerp law court. Retrieved from https://loc.alize.us/\#/geo:51.204504,4.388287,17,k/

Maetens, B. (2012). The long way home. Retrieved from: www.youtube.com/watch?v=mzGzyEtzZC8

Novosibdom. (2014). Antwerp Law Courts. Retrieved from: http://arx.novosibdom.ru/node/1996

RSH-P. (2014). Antwerp Law Courts. Retrieved from http://www.rsh-p.com/render.aspx?siteID=1\&navIDs=1,4,25,238

SCENIHR. (2012). Health Effects of Artificial Light. Scientific Committee on Emerging and Newly Identified Health Risks (SCENIHR).

Scubageek. (2005). External Reflection from a Water Surface. Retrieved from http://scubageek.com/articles/wwwatw.html 
Timbakote. (2014). timbakote natural timber finishes light reluctance value. Retrieved from http://www.timbakote.co.nz/site/timbakote/files/LRV\%20Chart.pdf

WHO. (1997). Jantunen M., Jaakkola J. J. K., Krzyzanowski M. (Eds). Assessment of exposure to indoor air pollutants. European Series, No. 78. World Health Organisation Regional Publications, Copenhagen.

\section{Copyrights}

Copyright for this article is retained by the author(s), with first publication rights granted to the journal.

This is an open-access article distributed under the terms and conditions of the Creative Commons Attribution license (http://creativecommons.org/licenses/by/3.0/). 